\title{
Family income, education and cognitive ability in the next generation: exploring income gradients in education and test scores for current cohorts of youth
}

\author{
Paul Gregg and Lindsey Macmillan \\ Centre for Public and Market Organisation and Department of Economics \\ University of Bristol \\ Lindsey.Macmillan@Bristol.ac.uk
}

(Received April 2010 Revised June 2010)

\section{Abstract}

The relationship between the incomes of the family a child is growing up in and the education level the child obtains, has been of great interest to researchers for a number of reasons. Firstly, this gives us a measure of educational inequality in its own right, and secondly, because the relationship between family income and education is also one of the key drivers of intergenerational income mobility across time in the UK, and gradients in life chances across a range of other domains. This paper explores the evolution of the relationship between family income and education, for a group of cohorts from those born in 1958 to those born in 1991/92. The range of educational relationships we can measure depends on the age of the child. For older cohorts, whom we assume have completed their education, we can measure the full range of educational outcomes up to degree level, and their relationship with family income. For younger cohorts who are in earlier stages of education, we can measure test scores and GCSE results but not later educational outcomes.

JEL Classifications: J62, J13, J31

\section{Key words}

Intergenerational mobility, children, education

\section{Introduction and previous literature}

The relationship between the incomes of the family a child is growing up in and the education level and cognitive abilities of the child, has been of great interest to researchers for a number of reasons. Firstly, this gives us a direct measure of educational inequality in its own right, and secondly, because the relationship between family income, education and earlier cognitive test scores is also one of the key drivers of intergenerational income mobility across time in the UK (Blanden, Gregg and Macmillan 2007) and gradients in life chances across a range of other domains.

There have been a number of recent studies exploring whether family income actually influences a child's educational attainment, or rather is just a marker for many other aspects of social (dis)advantage such as parents education level, social class etc. Dahl and Lochner (2008) exploit the introduction of the Earned Income Tax Credit in the US, Milligan and Stabille (2006) explore the variation in child benefits across time and Canadian provinces, and Gregg et al (2010) use fathers' job displacement. All of the studies suggest that sustained income shocks do impact on child educational outcomes and Oreopolous et al (2008) and Gregg et al (2010) suggest that this also influences intergenerational mobility.

Likewise there have been a large number of studies assessing whether a person's education actually does impact on outcomes, or whether it is instead reflecting other underlying abilities and attitudes. A number of studies have considered what happens when the school leaving age is 
raised, to attempt to identify a causal relationship between education and outcomes. For example, Meghir and Palme (2005) Oreopoulus (2006) and Dickson (2009) explore the impact on a person's earnings as an adult, Black et al (2008) look at teen pregnancy, and Orepolous and Page (2006), on a person's children's education. Again, all of these studies suggest that educational attainment has a direct causal influence on life chances.

Given the evidence that income causally impacts education and education causally impacts outcomes, the strength of the relationship between family background and a child's education attainment, represents the extent to which adult outcomes mirror the individual's childhood circumstances, and are thus an indicator of equality of opportunity. This may mean that an individual, who is born into a poor family, faces life-long penalties regardless of their own abilities or effort. For this reason, this is currently a highly topical area in the UK, where the notion of 'opportunity for all' has been cited as a central policy goal by all three major political parties. This has resulted in a number of policy initiatives, a government white paper on social mobility, and a Commission on Fair Access to the Professions chaired by a former Cabinet Minister, Alan Milburn (the Milburn Commission).

There has been a large literature centred on the measurement of mobility, and more recently on both international comparisons and cross-cohort comparisons for the UK. The broad consensus is that in international terms, the UK has a low level of mobility (Solon 2002, Corak 2006), rivalled only by the United States, and across cohorts, the UK's level of intergenerational income mobility declined between cohorts born in 1958 and those born in 1970 (Blanden et al 2004). For policy makers, one of the main problems when attempting to think about intergenerational mobility is the need for individual level data over a large number of years. To capture an intergenerational elasticity, information is needed on the individual's family socio-economic status in childhood, and on the individual's own socio-economic status in adulthood. Previous research from the cohort studies provides evidence on the levels of mobility for children growing up in the 1970 s and the 1980 s. Policy makers wishing to assess the impact of recent policy innovations on social mobility, will therefore have to wait at least another decade until the children experiencing these policy innovations have reached an age in the labour market, where their own financial circumstances are fully apparent.

This research will therefore estimate the relationships between family income and education, in terms of both educational attainment and earlier cognitive test scores, for a group of cohorts from those born in 1958 to those born in $1991 / 92$. This in itself is a valuable addition to the current literature, given the variety of data sources that we use. The range of educational relationships we can measure obviously depends on the age of the child. For older cohorts, whom we assume to have completed their education, we can measure the full range of educational outcomes up to degree level, and their relationship with family income. For younger cohorts who are in earlier stages of education, we can measure earlier test scores and GCSE results, but not later educational outcomes. Although it is beyond the scope of this research to examine the direct relationship between cognitive abilities and educational attainment, we draw upon other literature that finds strong correlations between the two in the UK (Deary et al 2007). We therefore use these test scores as a good proxy for later educational attainment for children that we do not yet observe educational attainment for.

In the next section we lay out our modelling approach in more detail. In section 3 we discuss the data sources used before presenting our results in section 4 . Section 5 offers conclusions.

\section{Methodology}

The main objective in this paper is to say something about the changing relationship between family income and educational outcomes across a range of cohorts. The relationship of interest for examining the association between the family income of the child and their educational attainment and cognitive abilities, is captured by $\lambda$ in the following regression, where $E d_{i}$ is a range of measures from test scores to degree attainment. The parental income variable is logged to ensure that the relationship is constant across the distribution of income; a $10 \%$ increase in the standard of living is the same for a family in the $10^{\text {th }}$ percentile of the income distribution compared to the $90^{\text {th }}$ percentile.

$$
E d_{i}=\alpha+\lambda \ln Y_{i}^{\text {Parents }}+\text { Sage }_{i}+\pi a g e_{i}^{2}+\text { female }_{i}+\varepsilon_{i}
$$


Quadratic age controls for the parents are included to adjust for life-cycle biases in family income, and a gender dummy is included to account for the differential educational experiences of males and females in each of the surveys.

\section{Data}

For this analysis, we use the two British birth cohorts, as in Blanden et al (2007). In addition, we introduce three younger cohorts using data from the UK household panel study and two new cohorts where the focus children have just completed compulsory education.

The National Child Development Study is a study of those born in 1958 and the British Cohort Study is a study of those born in 1970. Both cohorts, run by the Centre for Longitudinal Studies (CLS) at the Institute of Education (IOE), London, began with around 18,000 children. Our final samples are reduced to around 5,000-7,000 respondents, given the requirement of parental income information and educational attainment. The issue of attrition in the cohorts is explored in greater detail in the robustness section. The National Child Development Study (NCDS) obtained data at birth and ages $7,11,16,23,33,42$, 46 and 50 for children born in a week in March 1958. The BCS originally included all those born in Great Britain in a week in April 1970. Information was obtained about the sample members and their families at birth and at ages 5, 10, 16, 26, 30, 34 and 38 (for more details see http://www.cls.ioe.ac.uk).

The British Household Panel Survey (BHPS) is not a birth cohort. It is run by the Institute for Social and Economic Research (ISER) at the University of Essex and tracks a representative sample of 10,000 households from 1991 onwards (http://www.iser.essex.ac.uk/survey/bhps). As it is a household panel study, members of the original households' from 1991 are followed into new households, including any children, after leaving the family home. Hence, the BHPS can track small numbers of children who reach age 16 in any year through to adulthood. However, as these samples are small, we pool a number of years to create cohort windows of people entering in waves 1-6 (BHPS 1) that are born in 1975-1980, those entering in waves 7 12 (BHPS 2) that are born in 1981-1986, and those entering in waves 13-16 (BHPS 3 ) that are born in 1987-1990. Despite these attempts however, the samples remain small, at around 900 children for our oldest cohort and 300 for our youngest. Statistical inference is therefore a problem for this data.

The LSYPE is a longitudinal survey of young people, collected by the Department for Children, Schools and Families (DCSF), who were aged 13/14 in 2004 and so were born in 1989 and 1990 (http://www.esds.ac.uk/longitudinal/access/lsype) $\underline{\text { L5545.asp). }}$. These individuals were beginning junior school in 1997 with the change in UK Government and have thus been exposed to national policy developments in the New Labour period. The survey follows the young people and their families with data currently available up to wave 4, 2007 at age 17/18. These individuals are therefore comparable with our third cohort of BHPS individuals, as they have just finished their GCSEs. The additional benefit of the LSYPE is that it is a large survey with around 14,000 participants in wave 1 , and around 11,000 respondents for our purposes. We are therefore able to gain much stronger inferences from using this sample.

ALSPAC is a birth cohort of children born in the former region of Avon (an area centred on Bristol) from 1991 to 1992, making them a very similar age to those in the LSYPE. The collection and provision of this data is available directly from ALSPAC, based within the University of Bristol (http://www.bristol.ac.uk/alspac/). Due to data backlogs, data is only available for these individuals up to the age of 11 currently, so there is no information available on later educational attainment. Information is available however for Key Stage 2 test scores and an IQ clinic measure.

Table 1 summarizes all of the available information for analysing the relationship between family income, educational attainment and test scores. Much work has been done to ensure that the income, education and test score measures are comparable, and that any attrition from these large surveys is not driving the main findings of this research. This will be discussed in greater detail at the end of the results section. 
Table 1. Observable data for second stage analysis

\begin{tabular}{lccccccc} 
Data source & NCDS & BCS & BHPS 1 & BHPS 2 & BHPS 3 & LSYPE & ALSPAC \\
\hline Year of birth & 1958 & 1970 & $1975 / 80$ & $1981 / 86$ & $1987 / 90$ & $1989 / 90$ & $1991 / 92$ \\
\hline Family income & $\mathrm{V}$ & $\mathrm{V}$ & $\mathrm{V}$ & $\mathrm{V}$ & $\mathrm{V}$ & $\mathrm{V}$ & $\mathrm{V}$ \\
(age) & $(16)$ & $(16)$ & $(16-18)$ & $(16-18)$ & $(16-18)$ & $(14)$ & $(11)$ \\
IQ at 8/10/11 & $\mathrm{V}$ & $\mathrm{V}$ & & & & & $\mathrm{V}$ \\
Reading at & $\mathrm{V}$ & $\mathrm{V}$ & & & & $\mathrm{V}$ & $\mathrm{V}$ \\
7/10/11 & & & & & & $\mathrm{V}$ & $\mathrm{V}$ \\
Maths at 10/11 & $\mathrm{V}$ & $\mathrm{V}$ & & & & $\mathrm{V}$ & \\
No. of GCSEs & $\mathrm{V}$ & $\mathrm{V}$ & $\mathrm{V}$ & $\mathrm{V}$ & $\mathrm{V}$ & $\mathrm{V}$ & \\
Staying on at 16 & $\mathrm{V}$ & $\mathrm{V}$ & $\mathrm{V}$ & $\mathrm{V}$ & $\mathrm{V}$ & & \\
No. of A-levels & $\mathrm{V}$ & $\mathrm{V}$ & $\mathrm{V}$ & $\mathrm{V}$ & & & \\
Staying on at 18 & $\mathrm{V}$ & $\mathrm{V}$ & $\mathrm{V}$ & $\mathrm{V}$ & & & \\
Degree & $\mathrm{V}$ & $\mathrm{V}$ & $\mathrm{V}$ & $\mathrm{V}$ & & & \\
Early labour & $\mathrm{V}$ & $\mathrm{V}$ & $\mathrm{V}$ & & & & \\
market & & & & & & & \\
\hline Aget & & & & & &
\end{tabular}

Age at which family income is available in parenthesis

\section{Income measures}

Parental income data is available at age 16 in both of the older birth cohort studies. In the NCDS, the data is banded for mother's earnings, father's earnings and other income, with an average of the mid-points of all three categories used as a final broadly continuous measure. In the BCS, parental income is derived from information obtained at age 16. We generate continuous income variables by fitting a Singh-Maddala distribution (Singh and Maddala 1976) to the data using maximum likelihood estimation. This is particularly helpful in allocating an expected value for those in the open top category. We then adjust the income variable to a net measure, using the FRS (1986), and impute child benefit for all families. Furthermore both of the income measures are standardised, as with all other income measures, to mean 0 , standard deviation 1. This is to ensure that changes in income inequality across the cohorts or small changes in the variance in income due to minor definitional or reporting differences, will not drive the results. These measures have been used on a number of occasions and a great deal of work has been done already to test their robustness and comparability
(Blanden 2004, Blanden, Gregg and Macmillan 2010).

In the BHPS, the family income of the parents is observed when the study children enter the survey at age 16. The family income measure is taken from the 'Derived current and annual net household income' dataset, an unofficial supplement to the derived gross income variables released with the BHPS. The income measure is adjusted to monthly income, logged and standardised for comparability.

For the LSYPE, the income measure is created using data from wave 1 , when the cohort members are 14. The original family income measure in the LSYPE is gross banded income including benefits. The measure is coded to monthly income, and the measure is transformed from gross to net using information from the Family Resources Survey (FRS 2004). There are a large number of bands in the LSYPE, with only two individuals falling into the open top category, so a Singh-Maddala transformation is unnecessary in this case. An interval regression technique is then used instead, to distribute the families within each band. As with all income measures, the measure is logged and standardised to mean 0 , standard deviation 1 . A number of robustness tests are carried out to assess 
the impacts of using different methods to create comparable income measures, which are discussed in the results section. Given that the LSYPE is a study of young people in England, robustness tests are also carried out on the significant results for sub-samples of the other cohorts from England only.

The income measure from ALSPAC is taken from banded household net income at age 11 and put through the same Singh-Maddala process as that which is used to deal with banded income in the BCS. The measure is then logged before being standardised to mean 0 , standard deviation 1 . Robustness tests using income at 10 from the BCS, show that education and test score income gradients using earlier income measures are comparable, given high levels of persistence in income.

\section{Educational attainment measures}

Educational attainments were obtained from information provided at ages 16, 23 and 33 in the NCDS and ages 16, 26 and 30 for the BCS sample. This includes detailed information on the number of exams passed (both GCE 'O' level and CSE (Certificate of Secondary Education)). Information on educational achievements beyond age 16 is also available at these ages. The GCSE measure we construct is the number of O-levels graded A-C obtained by the cohort member, and the A-level measure is the total number of A-levels obtained where an A/S level (taken halfway through the 2year course of study) counts for half an A-level. The two staying on variables are dummies to capture staying on decisions at 16 and 18 , and the degree measure is also a dummy to measure degree attainment. In addition, information on all periods of labour market and educational activity from age 16 to 24 can be derived from an additional work history data source, available for every month from age 16 to 42 (NCDS) and 16 to 30 (BCS). This information is used to generate the measure of labour market attachment, which is the proportion of months between leaving full-time education and age 24 , when the individual is not in education, employment or training.

For the first BHPS cohort, BHPS 1, we can observe educational attainment measures constructed in the same way as the cohort studies, and the proportion of time since leaving full-time education that they have spent not in education, employment or training, comparable with the two birth cohorts. For the second cohort, BHPS 2, we can observe all individuals' educational attainment until the age of 20. As we do not observe them later than 20, there is no information on their labour market attachment, and the degree variable also includes individuals who are at university but have not yet necessarily completed their degree. All other measures remain consistent with previous cohorts. The third BHPS cohort, BHPS3, can only be observed until the age of 17 . We can therefore use measures of educational attainment between 16 and 17 but no further.

LSYPE educational attainment is created using administrative data from Key Stage 4 to create a total number of GCSEs level $A^{*}-C$ measure. In addition, information from wave 4 on the main activity of the young person is used to create a dummy indicator for staying in education post- 16 . Given concerns that grade inflation might affect the relationship between family income and educational attainment over time, more restrictive measures of GCSE attainment are also used for robustness checks. The problem is that, if there is grade inflation, the distribution of grades will get more compressed around the top of the distribution, because the top of the scale is capped and will cause lower attaining groups to appear to catch up with higher attaining ones. Measures of attainment that are more demanding, will have lower means at all parts of the distribution when expressed as dummy variables, and thus are not so prone to this problem. The measures, which are comparable with measures constructed in the BCS, include the total points score, a dummy variable for obtaining $5 \mathrm{~A}^{*}$ - $C$ grades and a dummy variable indicating those who have obtained $5 \mathrm{~A}^{*}$ - $C$ grades including maths and english. This will be discussed in greater detail in our robustness section.

\section{Earlier test score measures}

When we look to bring in younger cohorts by comparing the relationship between income and earlier test scores, information is available in the NCDS at age 7 and 11 and the BCS at age 10. The reading, maths and IQ tests are broadly comparable across the cohorts from ages 11 and 10 respectively, with an additional reading measure atage 7 used from the NCDS for comparability with a similar measure from ALSPAC. All test scores in the cohorts are administered by the cohort studies 
and standardised to mean 0 , standard deviation 1 for comparison. The birth cohorts test scores have been used comparatively in a number of studies in the past including Galindo-Rueda and Vignoles (2005) and (Schoon 2006).

In the BHPS, given that the study children do not enter the panel until age 16 , we have no comparable early test scores available for these three cohorts. However in the LSYPE, we can also observe earlier outcomes for these individuals, as administrative data has been linked into the study including Key Stage 2 test scores. We can therefore extend our analysis to include the relationship between family incomes and test scores for this cohort of individuals, as with the cohort studies. Key Stage 2 scores are constructed using the discrete level obtained, and adjusting for the marks within each level, to create a 'fine point's score' for both reading and maths. These scores are then standardised to mean 0 , standard deviation 1 .

We can also introduce the ALSPAC cohort at this point, as although later educational attainment is not yet available in this data, earlier test score information is. The IQ measure from ALSPAC is slightly earlier than the cohorts at aged 8 , but as IQ measures are seen as a more permanent measure of intelligence, this may not be a major concern. The maths and reading scores are taken from the Key Stage 2 individual test marks, in the same way they are derived in the LSYPE. As with the cohort studies and LSYPE, the three scores are standardised to mean 0 , standard deviation 1 .

To ensure that there are no concerns over differences between the tests administered by the cohort studies and the key stage tests which children may be 'taught to', we also include for robustness a reading test at 7 administered in an ALSPAC clinic at 7. This is again standardised to mean 0 , standard deviation 1 . The correlation between the reading test at 7 and that of the reading component of key stage 2 at 11 is high, with a correlation coefficient of 0.6766 .

\section{Results}

The relationship between family income and educational attainment

We start by showing the patterns of the number of GCSE $A^{*}$ to $C$ grades achieved for each cohort we can consider. Table 2 shows this information by family income quintile.

Table 2. Average number of GCSE O-levels or equivalent at grade $A^{*}-C$ by income quintile for NCDS, BCS, BHPS 1 (1975-80), BHPS 2 (1981-86), BHPS 3 (1987-1990) and LSYPE (1989-90)

\begin{tabular}{lcccccc} 
& NCDS & BCS & BHPS 1 & BHPS 2 & BHPS 3 & LSYPE \\
& $\mathbf{1 9 5 8}$ & $\mathbf{1 9 7 0}$ & $\mathbf{1 9 7 5 - 1 9 8 0}$ & $\mathbf{1 9 8 1 - 1 9 8 6}$ & $\mathbf{1 9 8 7 - 1 9 9 0}$ & $\mathbf{1 9 8 9 / 1 9 9 0}$ \\
\hline Inc quintile 1 & 1.6153 & 2.6693 & 3.9149 & 4.5952 & 4.6364 & 3.6972 \\
Inc quintile 2 & 1.9673 & 3.2020 & 4.7485 & 5.8197 & 4.5672 & 3.9431 \\
Inc quintile 3 & 2.2362 & 3.7363 & 5.1299 & 6.0083 & 6.1558 & 4.8232 \\
Inc quintile 4 & 2.5081 & 4.4377 & 5.5538 & 6.2897 & 6.4746 & 5.7901 \\
Inc quintile 5 & 3.6936 & 5.7410 & 6.7162 & 6.6220 & 7.2632 & 7.3534 \\
\hline
\end{tabular}

Unconditional means by income quintile, boys and girls

As has been widely observed, there has been a steady increase in numbers of $O$ levels / GSCEs secured across the cohorts. The NCDS cohort sat $O$ levels (the precursor to GCSEs) in 1974 when a large proportion of the cohort would have entered into selective education. Although most schools moved to be comprehensives by 1974 , those attending secondary moderns (and former secondary moderns) were much less likely to be entered for 0 levels at this time. In this cohort the average child got just over $2 \mathrm{~A}-\mathrm{C}$ grade $\mathrm{O}$ levels. The cohort of the
BCS sat O levels (also known as GCEs (General Certificate of Education) and CSEs (Certificate of Secondary Education) where the top grade of the latter was equivalent to a GCSE grade C) in 1986 and on average, pupils obtained just under $4 \mathrm{O}$ levels or top CSEs. This was just before the implementation of reforms laid out by Sir Keith Joseph, which moved the examination system from one where essentially a fixed proportion of students could get any particular A-C grade (around one third) to there being a fixed line over which any 
number could pass. The subsequent increase in the proportion getting higher grades has lead to concerns over grade inflation, where it has been argued that exam standards are falling.

The BHPS 1 cohort sat the new combined GCSEs from 1991 to 1996, after a period of rapid increase in GCSE attainment which has continued since at a slower rate. This generation was now achieving $51 / 2$ GCSE A*-Cs. The BHPS can add new five year cohort data here, a second and third more recent BHPS cohort born between 1981 and 1986 (BHPS 2) and 1987 to 1990 (BHPS 3) who were achieving an average of 6 GCSEs $A^{*}-C$ grades per pupil. The LYPSE cohort, tracked since they were 14, has just turned 17, and whilst we have GCSE result for those taken at age 16 in the academic year 2005/2006, this cohort lacks any information regarding those sitting the exams at ages $17+$. This means the mean number of GCSEs $A *-C$ grade students achieve inthe LYPSE cohort is a little below that of the preceding BHPS cohorts.

In what follows next, we explore how the attainment gaps have changed across these different cohorts. So, we need to get an idea of the direction of any bias, that may arise from the lack of exam data referred to above, for those sitting additional GCSEs at age $17+$ in the LYPSE. The Department of Children, Schools and Families (DCSF) reported on the proportion of young adults obtaining 5 or more $A^{*}-C$ grade GCSEs, as the required level 2 attainment at ages 16 to 19 in 2007. These figures included vocational qualifications that can also be ranked as level 2 attainments. The figures from DCSF, shown in Table 3 , suggest that level 2 attainment increases through to age 19. This table illustrates attainment by those in receipt of Free School Meals (FSM) and non-FSM students, a commonly-used proxy for family income, as this does not exist in Government data. The table summarizes both the gap between the percentage of FSM and non-FSM level 2 attainment, and the likely relative odds of reaching this attainment for both categories. For example, a nonFSM child is twice as likely at age 16 to reach a level 2 attainment relative to an FSM child.

Table 3. Proportion of FSM and non-FSM individuals obtaining 5 or more GCSEs or equivalent at grade $A$ *C for those born 1989-1992 by age in 2008

\begin{tabular}{lcccc} 
Age in 2008 & $\mathbf{1 6}$ & $\mathbf{1 7}$ & $\mathbf{1 8}$ & $\mathbf{1 9}$ \\
\hline Non-FSM & 58.2 & 66.6 & 73.6 & 76.9 \\
FSM & 29.4 & 39.5 & 48.4 & 53.2 \\
\hline Difference & $\mathbf{2 8 . 8}$ & $\mathbf{2 7 . 1}$ & $\mathbf{2 5 . 2}$ & $\mathbf{2 3 . 7}$ \\
\hline Ratio & $\mathbf{1 . 9 8}$ & $\mathbf{1 . 6 9}$ & $\mathbf{1 . 5 2}$ & $\mathbf{1 . 4 5}$
\end{tabular}

Source: http://www.dcsf.gov.uk/rsgateway/DB/SFR/s000835/index.shtml - Additional level 2 qualifications by FSM 2008

The rise by age 17 is primarily through GCSEs obtained, rather than two year vocational courses, and this extension adds another $9 \%$ of students achieving 5+ $A *-C$ GCSEs. Crucially here, the FSM/nonFSM gap narrows by 1.7 percentage points, as most of those already achieving $5+$ passes go on to level 3 courses (mainly A-Levels), but some of those just missing this benchmark do further exams. Furthermore, information from wave 4 of LYPSE, on the main activity of the young person, can shed further light on the likely direction of this bias. Looking directly at the LSYPE data, for those young people who report in wave 4 that they are staying on at school or college full-time to study for GCSEs, the average family income at 14 was just $£ 1432.66$ per month, compared to the sample average of $f 1841.35$. Hence the bias from missing later GCSE exam information for the most recent cohort, is likely to overstate the relationship between family background and educational attainment, as later information reduces the gap between higher and lower income children.

Table 2 shows how, as well as a rise in the average number of passes, there was increasing numbers of passes for all quintiles of income. However, between the NCDS and BCS this occurred more slowly for the poorest income group ( 1 extra $A^{*}-C$ pass) than for the middle (1.5 passes) and for the top quintile (2 passes). Since then, increases in pass rates were slightly faster at the middle (1.4 extra passes) and bottom (1.2) than at the top (1) between the BCS and first of the BHPS 
cohorts. This pattern has continued through the available BHPS data.

Table 4 shows the separate univariate relationships between family income and all education qualification levels, and the proportion of time spent not in education, employment or training (NEET) before age 24 (see equation (1) for each cohort, where the data is available). Across all five cohorts, those individuals from better off families did better at every stage of educational attainment than their less well off counterparts, and were less likely to spend a proportion of their early labour market experiences as a NEET The number of GCSE $A^{*}-C$, the number of Alevels achieved and attachment to the labour market variables are estimates using OLS and our staying on post-16, post-18 and degree measures are estimates using the Linear Probability Model (LPM). The coefficients can therefore be interpreted, in terms of a standard deviation increase in income, as a unit increase for the OLS models, (an increase of 1 GCSE at grade $A^{*}-C$ for a coefficient of 1 ) and as a percentage of likelihood for the LPM models ( $10 \%$ more likely to obtain a degree for a coefficient of 0.10 ).

Table 4. Relationship between standardised family income and education levels for NCDS, BCS, BHPS 1 (1975-80), BHPS 2 (1981-86), BHPS 3 (1987-90) and LSYPE (1989-90)

\begin{tabular}{|c|c|c|c|c|c|c|}
\hline Variable & $\begin{array}{l}\text { NCDS } \\
1958 \\
\end{array}$ & $\begin{array}{l}\text { BCS } \\
1970\end{array}$ & $\begin{array}{l}\text { BHPS 1 } \\
1975-1980\end{array}$ & $\begin{array}{l}\text { BHPS 2 } \\
1981-1986 \\
\end{array}$ & $\begin{array}{l}\text { BHPS } 3 \\
1987-1990 \\
\end{array}$ & $\begin{array}{l}\text { LSYPE } \\
1989 / 1990 \\
\end{array}$ \\
\hline Number of O- & 0.7165 & 1.1315 & 1.0647 & 0.7958 & 0.9880 & 0.9336 \\
\hline levels ( $A *-C)$ & {$[0.036]^{* * *}$} & {$[0.046]^{* * *}$} & {$[0.155]^{* * *}$} & {$[0.258]^{* * *}$} & {$[0.249]^{* * *}$} & {$[0.035]^{* * *}$} \\
\hline$N$ & 7841 & 5428 & 815 & 515 & 345 & 10935 \\
\hline \multirow[t]{2}{*}{ Stay on post -16} & 0.0963 & 0.1360 & 0.1110 & 0.0846 & 0.0885 & 0.0463 \\
\hline & {$[0.006]^{* * *}$} & {$[0.006]^{* * *}$} & {$[0.019]^{* * *}$} & {$[0.031]^{* * *}$} & {$[0.029]^{* * *}$} & {$[0.005]^{* * *}$} \\
\hline$N$ & 7196 & 6420 & 964 & 583 & 386 & 8205 \\
\hline Number of A- & 0.1618 & 0.4164 & 0.4703 & 0.4512 & & \\
\hline levels (any) & {$[0.010]^{* * *}$} & {$[0.023]^{* * *}$} & {$[0.075]^{* * *}$} & {$[0.128]^{* * *}$} & & \\
\hline$N$ & 7841 & 3769 & 638 & 373 & & \\
\hline \multirow[t]{2}{*}{ Stay on post -18} & 0.0621 & 0.1047 & 0.0697 & 0.0730 & & \\
\hline & {$[0.004]^{* * *}$} & {$[0.006]^{* * *}$} & {$[0.021]^{* * *}$} & {$[0.033]^{* *}$} & & \\
\hline$N$ & 7196 & 5529 & 946 & 568 & & \\
\hline \multirow[t]{2}{*}{ Degree } & 0.0553 & 0.1158 & 0.0916 & 0.0884 & & \\
\hline & {$[0.004]^{* * *}$} & {$[0.006]^{* * *}$} & {$[0.017]^{* * *}$} & {$[0.033]^{* * *}$} & & \\
\hline$N$ & 7949 & 5520 & 932 & 484 & & \\
\hline Proportion time & -0.0049 & -0.0197 & -0.0676 & & & \\
\hline NEET & {$[0.002]^{* * *}$} & {$[0.003]^{* * *}$} & {$[0.009]^{* * *}$} & & & \\
\hline$N$ & 5907 & 5546 & 949 & & & \\
\hline
\end{tabular}

Standard errors in parentheses, boys and girls, controls for parental age, parental age squared and gender

$* * *$ Indicates significance at the $99 \%$ confidence level, $* *$ is significant at the $95 \%$ confidence level, and * indicates a $90 \%$ confidence level.

Family income is monthly net logged standardised family income. Income standardised to account for differential variation across cohorts.

The strength of the relationship between family income and educational outcomes increased between those born in 1958 and 1970 for all six outcomes considered. As an example, using standardised income to net out any effect from rising wage inequality, a doubling of family income in the NCDS was associated with an individual being $6 \%$ more likely to gain a degree, whereas in the BCS the same increase saw an individual being $11 \%$ more likely to gain a degree. The BHPS cohorts suggest this was around $9 \%$ for those born in the late 1970s and early 1980s.

The BHPS analysis is based on far smaller data, and so the results need to be assessed with care.Table 5 reports joint tests of significant changes in the coefficients across various cohort comparisons. This was assessed by jointly 
estimating the pooled cohorts with an interaction term for the later cohort. If the interaction was significant, the estimate is observed as significantly different from the previous cohorts estimate.Column 3 indicates that the increase in the relationship between income and education in the
BCS, compared to the NCDS, is significant for every education level and for the early labour market experience. For the BCS, a doubling in income was associated with a gain of an extra half of a GCSE at $A^{*}$-C level, over that achieved by their NCDS counterparts.

Table 5. Cross-cohort tests of significant differences from table 4 results

\begin{tabular}{|c|c|c|c|}
\hline Variable & $\begin{array}{l}\text { NCDS } \\
1958\end{array}$ & $\begin{array}{l}\text { BCS } \\
1970\end{array}$ & $\begin{array}{l}\text { Cross-cohort } \\
\text { Difference }\end{array}$ \\
\hline $\begin{array}{l}\text { Number of O-levels } \\
\left(A^{*}-C\right)\end{array}$ & $\begin{array}{l}0.7165 \\
{[0.036]^{* * *}}\end{array}$ & $\begin{array}{l}1.1315 \\
{[0.046]^{* * *}}\end{array}$ & $\begin{array}{l}0.4150 \\
{[0.058]^{* * *}}\end{array}$ \\
\hline Stay on post - 16 & $\begin{array}{l}0.0963 \\
{[0.006]^{* * *}}\end{array}$ & $\begin{array}{l}0.1360 \\
{[0.006]^{* * *}}\end{array}$ & $\begin{array}{l}0.0397 \\
{[0.008]^{* * *}}\end{array}$ \\
\hline $\begin{array}{l}\text { Number of A-levels } \\
\text { (any) }\end{array}$ & $\begin{array}{l}0.1618 \\
{[0.010]^{* * *}}\end{array}$ & $\begin{array}{l}0.4164 \\
{[0.023]^{* * *}}\end{array}$ & $\begin{array}{l}0.2546 \\
{[0.021]^{* * *}}\end{array}$ \\
\hline Stay on post - 18 & $\begin{array}{l}0.0621 \\
{[0.004]^{* * *}}\end{array}$ & $\begin{array}{l}0.1047 \\
{[0.006]^{* * *}}\end{array}$ & $\begin{array}{l}0.0426 \\
{[0.007]^{* * *}}\end{array}$ \\
\hline Degree & $\begin{array}{l}0.0553 \\
{[0.004]^{* * *}}\end{array}$ & $\begin{array}{l}0.1158 \\
{[0.006]^{* * *}}\end{array}$ & $\begin{array}{l}0.0604 \\
{[0.006]^{* * *}}\end{array}$ \\
\hline Proportion time NEET & $\begin{array}{l}-0.0049 \\
{[0.002]^{* * *}}\end{array}$ & $\begin{array}{l}-0.0197 \\
{[0.003]^{* * *}}\end{array}$ & $\begin{array}{l}-0.0147 \\
{[0.003]^{* * *}}\end{array}$ \\
\hline Variable & $\begin{array}{l}\text { BCS } \\
1970\end{array}$ & $\begin{array}{l}\text { BHPS 1 } \\
1975-1980\end{array}$ & $\begin{array}{l}\text { Cross-cohort } \\
\text { Difference }\end{array}$ \\
\hline $\begin{array}{l}\text { Number of O-levels } \\
\left(A^{*}-C\right)\end{array}$ & $\begin{array}{l}1.1315 \\
{[0.046]^{* * *}}\end{array}$ & $\begin{array}{l}1.0647 \\
{[0.155]^{* * *}}\end{array}$ & $\begin{array}{l}-0.0669 \\
{[0.162]}\end{array}$ \\
\hline Stay on post - 16 & $\begin{array}{l}0.1360 \\
{[0.006]^{* * *}}\end{array}$ & $\begin{array}{l}0.1110 \\
{[0.019]^{* * *}}\end{array}$ & $\begin{array}{l}-0.0251 \\
{[0.021]}\end{array}$ \\
\hline $\begin{array}{l}\text { Number of A-levels } \\
\text { (any) }\end{array}$ & $\begin{array}{l}0.4164 \\
{[0.023]^{* * *}}\end{array}$ & $\begin{array}{l}0.4703 \\
{[0.075]^{* * *}}\end{array}$ & $\begin{array}{l}0.0539 \\
{[0.073]}\end{array}$ \\
\hline Stay on post - 18 & $\begin{array}{l}0.1047 \\
{[0.006]^{* * *}}\end{array}$ & $\begin{array}{l}0.0697 \\
{[0.021]^{* * *}}\end{array}$ & $\begin{array}{l}-0.0349 \\
{[0.019]^{*}}\end{array}$ \\
\hline Degree & $\begin{array}{l}0.1158 \\
{[0.006]^{* * *}}\end{array}$ & $\begin{array}{l}0.0916 \\
{[0.017]^{* * *}}\end{array}$ & $\begin{array}{l}-0.0241 \\
{[0.018]}\end{array}$ \\
\hline Proportion time NEET & $\begin{array}{l}-0.0197 \\
{[0.003]^{* * *}}\end{array}$ & $\begin{array}{l}-0.0676 \\
{[0.008]^{* * *}}\end{array}$ & $\begin{array}{l}-0.0480 \\
{[0.007]^{* * *}}\end{array}$ \\
\hline Variable & $\begin{array}{l}\text { BHPS 1 } \\
1975-1980\end{array}$ & $\begin{array}{l}\text { BHPS 2 } \\
1981-1986\end{array}$ & $\begin{array}{l}\text { Cross-cohort } \\
\text { Difference }\end{array}$ \\
\hline $\begin{array}{l}\text { Number of O-levels } \\
\left(A^{*}-C\right)\end{array}$ & $\begin{array}{l}1.0647 \\
{[0.155]^{* * *}}\end{array}$ & $\begin{array}{l}0.7958 \\
{[0.258]^{* * *}}\end{array}$ & $\begin{array}{l}-0.2689 \\
{[0.291]}\end{array}$ \\
\hline Stay on post - 16 & $\begin{array}{l}0.1110 \\
{[0.019]^{* * *}}\end{array}$ & $\begin{array}{l}0.0846 \\
{[0.031]^{* * *}}\end{array}$ & $\begin{array}{l}-0.0263 \\
{[0.036]}\end{array}$ \\
\hline $\begin{array}{l}\text { Number of A-levels } \\
\text { (any) }\end{array}$ & $\begin{array}{l}0.4703 \\
{[0.075]^{* * *}}\end{array}$ & $\begin{array}{l}0.4512 \\
{[0.128]^{* * *}}\end{array}$ & $\begin{array}{l}-0.0191 \\
{[0.144]}\end{array}$ \\
\hline Stay on post - 18 & $\begin{array}{l}0.0697 \\
{[0.021]^{* * *}}\end{array}$ & $\begin{array}{l}0.0730 \\
{[0.033]^{* *}}\end{array}$ & $\begin{array}{l}0.0033 \\
{[0.039]}\end{array}$ \\
\hline Degree & $\begin{array}{l}0.0916 \\
{[0.017]^{* * *}}\end{array}$ & $\begin{array}{l}0.0884 \\
{[0.033]^{* * *}}\end{array}$ & $\begin{array}{l}-0.0032 \\
{[0.036]}\end{array}$ \\
\hline
\end{tabular}


(Table 5 cont'd)

\begin{tabular}{|c|c|c|c|}
\hline Variable & $\begin{array}{l}\text { BCS } \\
1970\end{array}$ & $\begin{array}{l}\text { BHPS } 2 \\
1981-1986\end{array}$ & $\begin{array}{l}\text { Cross-cohort } \\
\text { Difference }\end{array}$ \\
\hline $\begin{array}{l}\text { Number of O-levels } \\
\left(A^{*}-C\right)\end{array}$ & $\begin{array}{l}1.1315 \\
{[0.046]^{* * *}}\end{array}$ & $\begin{array}{l}0.7958 \\
{[0.258]^{* * *}}\end{array}$ & $\begin{array}{l}-0.3357 \\
{[0.239]}\end{array}$ \\
\hline Stay on post - 16 & $\begin{array}{l}0.1360 \\
{[0.006]^{* * *}}\end{array}$ & $\begin{array}{l}0.0846 \\
{[0.031]^{* * *}}\end{array}$ & $\begin{array}{l}-0.0514 \\
{[0.032]}\end{array}$ \\
\hline $\begin{array}{l}\text { Number of A-levels } \\
\text { (any) }\end{array}$ & $\begin{array}{l}0.4164 \\
{[0.023]^{* * *}}\end{array}$ & $\begin{array}{l}0.4512 \\
{[0.128]^{* * *}}\end{array}$ & $\begin{array}{l}0.0349 \\
{[0.110]}\end{array}$ \\
\hline Stay on post - 18 & $\begin{array}{l}0.1047 \\
{[0.006]^{* * *}}\end{array}$ & $\begin{array}{l}0.0730 \\
{[0.033]^{* *}}\end{array}$ & $\begin{array}{l}-0.0317 \\
{[0.028]}\end{array}$ \\
\hline Degree & $\begin{array}{l}0.1158 \\
{[0.006]^{* * *}}\end{array}$ & $\begin{array}{l}0.0884 \\
{[0.033]^{* * *}}\end{array}$ & $\begin{array}{l}-0.0274 \\
{[0.031]}\end{array}$ \\
\hline Variable & $\begin{array}{l}\text { BHPS 1 } \\
1975-1980\end{array}$ & $\begin{array}{l}\text { BHPS } 3 \\
1987-1990\end{array}$ & $\begin{array}{l}\text { Cross-cohort } \\
\text { Difference }\end{array}$ \\
\hline $\begin{array}{l}\text { Number of O-levels } \\
\left(A^{*}-C\right)\end{array}$ & $\begin{array}{l}1.0647 \\
{[0.155]^{* * *}}\end{array}$ & $\begin{array}{l}0.9880 \\
{[0.249]^{* * *}}\end{array}$ & $\begin{array}{l}-0.0767 \\
{[0.276]}\end{array}$ \\
\hline Stay on post - 16 & $\begin{array}{l}0.1110 \\
{[0.019]^{* * *}}\end{array}$ & $\begin{array}{l}0.0885 \\
{[0.029]^{* * *}}\end{array}$ & $\begin{array}{l}-0.0224 \\
{[0.034]}\end{array}$ \\
\hline Variable & $\begin{array}{l}\text { BCS } \\
1970 \\
\end{array}$ & $\begin{array}{l}\text { BHPS } 3 \\
1987-1990\end{array}$ & $\begin{array}{l}\text { Cross-cohort } \\
\text { Difference }\end{array}$ \\
\hline $\begin{array}{l}\text { Number of O-levels } \\
\left(A^{*}-C\right)\end{array}$ & $\begin{array}{l}1.1315 \\
{[0.046]^{* * *}}\end{array}$ & $\begin{array}{l}0.9880 \\
{[0.249]^{* * *}}\end{array}$ & $\begin{array}{l}-0.1436 \\
{[0.218]}\end{array}$ \\
\hline Stay on post - 16 & $\begin{array}{l}0.1360 \\
{[0.006]^{* * *}}\end{array}$ & $\begin{array}{l}0.0885 \\
{[0.029]^{* * *}}\end{array}$ & $\begin{array}{l}-0.0475 \\
{[0.030]} \\
\end{array}$ \\
\hline Variable & $\begin{array}{l}\text { BCS } \\
1970\end{array}$ & $\begin{array}{l}\text { LSYPE } \\
1989 / 1990 \\
\end{array}$ & $\begin{array}{l}\text { Cross-cohort } \\
\text { Difference }\end{array}$ \\
\hline $\begin{array}{l}\text { Number of O-levels } \\
\left(A^{*}-C\right)\end{array}$ & $\begin{array}{l}1.1315 \\
{[0.046]^{* * *}}\end{array}$ & $\begin{array}{l}0.9336 \\
{[0.035]^{* * *}}\end{array}$ & $\begin{array}{l}-0.1979 \\
{[0.060]^{* * *}}\end{array}$ \\
\hline Stay on post - 16 & $\begin{array}{l}0.1360 \\
{[0.006]^{* * *}}\end{array}$ & $\begin{array}{l}0.0463 \\
{[0.005]^{* * *}}\end{array}$ & $\begin{array}{l}-0.0897 \\
{[0.007]^{* * *}}\end{array}$ \\
\hline
\end{tabular}

Standard errors in parentheses, boys and girls, controls for parental age, parental age squared and gender

$* * *$ Indicates significance at the $99 \%$ confidence level, $* *$ is significant at the $95 \%$ confidence level, and $*$ indicates a $90 \%$ confidence level.

The picture through the BHPS cohorts and the LYPSE, is for moderate reduction in the gradient of GCSE scores by family background, and more dramatically for staying on at age 16 . The relationship between income and education shows no significant changes between those born in the BCS and those born just 5-10 years more recently in BHPS 1 cohort (born between from 1975-1980 - in the second panel of table 5), with nearly all the coefficients being negative but small in magnitude, and insignificantly different from the BCS relationships. So the picture is one of stability for those two cohorts born in the 1970s and attending secondary school in the 1980 s and early 1990 s. However, the relationship between the proportion of time spent not in education, employment or training became significantly more graded by income across these two cohorts. A $100 \%$ increase in family income in the BCS, would reduce the proportion of time spent not in education, employment or training (NEET), between leaving full-time education and the age of 24 , by under $2 \%$, but the same increase for the BHPS 1 cohort would reduce this time by more than three times the magnitude, over $6 \%$. This is in line with much of the work done on NEETs recently, and indicates that this is a group of individuals who are still in need of a lot of help as they are increasingly constrained by their family background.

The second BHPS cohort, those born from 19811986 , show another small reduction in the income gradients associated with most educational attainment outcomes considered (the exception being staying on at age 18) compared with the earlier BHPS1 cohort. Whilst the coefficient for the number of $A^{*}-C$ grades achieved at GCSE level has 
come down markedly from the BCS (panel 4, table $5)$, the large standard errors associated with the small BHPS sample make it hard to judge if this is a true effect rather than sampling. If both the BCS and BHPS 2 cohort were to experience a doubling of their income, the gap in the number of $A^{*}-C$ graded GCSEs, between poorer and more affluent children, would be 0.34 smaller in the later cohort than for individuals born in 1970. An even smaller third cohort of individuals born from 1987 to 1990, BHPS 3 , exhibit a very similar pattern as the previous BHPS cohort, and hence a similar decrease in the social gradient of those obtaining $A^{*}-C$ graded GCSEs (panel 6, Table 5) relative to the BCS. However, even combining the two later BHPS to increase sample size still leads to imprecision in the estimates.

The much larger LSYPE cohort who were born towards the end of the BHPS 3 sample (1989-90) and who would have experienced their junior schooling and secondary schooling under New Labour, further show similar gradients as the last two BHPS cohorts, but here the results are now statistically significant. Column 6 of Table 4 and the final panel of Table 5 show that the coefficient on standardised family income for the LSYPE is in the same range as the BHPS 2 and BHPS 3 cohorts, but the standard errors are now much smaller and suggest that a doubling of family income induces a 0.93 increase in the number of GCSEs grades $A^{*}-C$ compared to 1.13 in the BCS and 0.72 in the old NCDS. The levelling off of the later BHPS data for children born 1981-1990 and the LSYPE is reassuring, and suggests that income gradients in GCSEs have begun to return to the days of the early 1970s. As noted above, the LSYPE can not yet take into account those (re-)taking GCSEs at age 17, which are more often drawn from poorer families. Hence, this relatively small reduction in the family income gradient with respect to GCSE passes may understate the full picture.

Data on staying on decisions post-age 16 are also available across all cohorts, and table 4 illustrates that the pattern of a decrease in the income gradient for those born after 1980, as seen for GCSEs, is replicated here. Across the BHPS cohorts, BHPS 1 again looks very similar in magnitude to that of the BCS, with a reduction in the income gradient kicking in for those born 1980-1986 and 19871990 ii. Again, the magnitude of the standard errors prevents any findings of significant differences for these two cohorts and the BCS (panels $4 \& 6$, table $5)$, but a doubling of family income in the BCS led to a $13 \%$ higher chance of staying on post-16 compared to only $8 \%$ in the BHPS 2 and BHPS 3 cohorts, a reduction of $5 \%$ in the income gradient. For the larger LSYPE cohort this difference is more pronounced, with a $9 \%$ statistically significant reduction in the income gradient from that of the BCS (panel 7, table 5). This is indicative of the widening access to post-16 education seen above, with $76 \%$ of individuals in the LSYPE cohort opting to stay on in full-time school or college post-16, showing that staying on post- 16 is becoming a route that the majority of individuals now take, regardless of their family background.

The data on further educational qualifications is only available up to BHPS 2, given the current age of the younger cohorts. From the data available, there is little suggestion of progress in patterns of the number of $A$ levels secured and degree participation since the BCS cohort, as shown in panel 4 of Table 5 . Hence the patterns suggest that family background is becoming less important in determining attainment at age 16, where the number securing GCSEs graded $A^{*}-C$ has risen sharply and allowed access to further education, but remains significant at post-16 education levels.

\section{Robustness to alternative measures}

The evidence presented so far, suggests an equalising in educational opportunities across family background at age 16, allowing greater access to post-16 education, but no equalisation beyond age 17 (albeit for older cohorts as the members of the most recent cohorts are not yet old enough to report this information). Given the importance of the findings, additional robustness checks need to be carried out to ensure that we can be confident of the results presented here.

First, we explore other data sources that can provide some information on the changing relationship between family background and educational attainment, but do not contain full income data. These are the Youth Cohort Studies, which contain social class rather than income but have a good time span, and second, administrative data on child progress (National Pupil Database) which has Free School Meals (FSM). This is a low income proxy as FSM apply to children who are eligible (though do not necessarily take up) these free meals on the basis of their parents entitlement 
to the major out-of-work benefits (Job Seekers Allowance, Income Support and Incapacity Benefit). An issue with both of these data sources, is that social class sizes and the proportion of the population entitlement to FSM are not constant across time, and hence populations of different sizes are being compared.

Tables 6 and 7 report official DCSF statistics from these two extra sources of data, for level 2 attainments by both FSM status and social class. Table 6 reports information on $5+A^{*}-C$ GCSEs between FSM and non-FSM children born from
1986 to 1992, and hence overlap with the BHPS3 and LSYPE cohorts described above. As in table 2, both the gap in attainment between FSM and nonFSM children, and the relative odds of the two, are reported in the tables. Consistent with the pattern report above, we see the growth in the proportion achieving good GCSEs across both groups, but at a slightly faster rate among the FSM group. Expressed as the odds ratio of achieving 5+ GCSE passes, this declines rapidly from 2.3 times more likely among non-FSM than FSM children, to 1.7 times by 2008.

Table 6. Proportion of FSM and non-FSM individuals obtaining 5 or more GCSEs or equivalent at grade $A^{*}-C$

\begin{tabular}{lccccccc} 
GCSE year & 2002 & 2003 & 2004 & 2005 & 2006 & 2007 & 2008 \\
\hline Birth year & $\mathbf{1 9 8 6}$ & $\mathbf{1 9 8 7}$ & $\mathbf{1 9 8 8}$ & $\mathbf{1 9 8 9}$ & $\mathbf{1 9 9 0}$ & $\mathbf{1 9 9 1}$ & $\mathbf{1 9 9 2}$ \\
\hline Non-FSM & 53.7 & 55.2 & 56.1 & 58.9 & 61 & 62.8 & 67.0 \\
FSM & 23.0 & 24.4 & 26.1 & 29.9 & 31 & 35.5 & 40.0 \\
\hline Difference & $\mathbf{3 0 . 7}$ & $\mathbf{3 0 . 8}$ & $\mathbf{3 0 . 0}$ & $\mathbf{2 9 . 0}$ & $\mathbf{2 9 . 5}$ & $\mathbf{2 7 . 3}$ & $\mathbf{2 7 . 0}$ \\
\hline Ratio & $\mathbf{2 . 3 3}$ & $\mathbf{2 . 2 6}$ & $\mathbf{2 . 1 5}$ & $\mathbf{1 . 9 7}$ & $\mathbf{1 . 9 5}$ & $\mathbf{1 . 7 7}$ & $\mathbf{1 . 6 8}$
\end{tabular}

Source: http://www.dcsf.gov.uk/rsgateway/DB/SFR/s000759/index.shtml National Curriculum Assessment, GCSE and Equivalent Attainment and Post-16 Attainment by Pupil Characteristics, in England 2002-2008

Table 7. Proportion of individuals obtaining 5 or more GCSEs or equivalent at grade $A^{*}-C$ by parental occupation groupings for those born 1972-1990

\begin{tabular}{|c|c|c|c|c|c|c|c|c|c|c|}
\hline GCSE year & '88 & ‘90 & ‘91 & ‘93 & ‘95 & ‘97 & ‘99 & ‘01 & ‘03 & ‘06 \\
\hline Birth year & 72 & '74 & '75 & 97 & 79 & '81 & '83 & '85 & '87 & '90 \\
\hline \multicolumn{11}{|l|}{$\begin{array}{l}\text { PARENTAL OCCUPATION } \\
\text { (SEG) }\end{array}$} \\
\hline Managerial/Professional & 52 & 58 & 60 & 66 & 68 & 69 & 70 & & & \\
\hline Other non-manual & 42 & 49 & 51 & 58 & 58 & 60 & 59 & & & \\
\hline Skilled manual & 21 & 27 & 29 & 36 & 36 & 40 & 45 & & & \\
\hline Semi-skilled manual & 16 & 20 & 23 & 26 & 29 & 32 & 35 & & & \\
\hline Unskilled manual & 12 & 15 & 16 & 16 & 24 & 20 & 30 & & & \\
\hline Top - Bottom & 40 & 43 & 44 & 50 & 44 & 49 & 40 & & & \\
\hline Ratio of top / bottom & 4.3 & 3.9 & 3.8 & 4.1 & 2.8 & 3.5 & 2.3 & & & \\
\hline \multicolumn{11}{|l|}{$\begin{array}{l}\text { PARENTAL OCCUPATION } \\
\text { (NS-SEC) }\end{array}$} \\
\hline Higher professional & & & & & & & 75 & 77 & 76 & 81 \\
\hline Lower professional & & & & & & & 62 & 64 & 65 & 73 \\
\hline Intermediate & & & & & & & 49 & 51 & 53 & 59 \\
\hline Lower supervisory & & & & & & & 34 & 34 & 41 & 46 \\
\hline Routine & & & & & & & 26 & 31 & 33 & 42 \\
\hline Top - Bottom & & & & & & & 49 & 46 & 43 & 39 \\
\hline Ratio of top / bottom & & & & & & & 2.9 & 2.5 & 2.3 & 1.9 \\
\hline
\end{tabular}

Source: http://www.dcsf.gov.uk/rsgateway/DB/SBU/b000795/Bulletin tables final.xls. LSYPE, wave 4 and YCS, cohorts 4-13, sweep 1 
Table 7 uses information from the slightly more informative YCS, given that it covers the BCS period and all the cohorts considered since then. It shows level 2 attainments by measures of head of households' social class. There is a break in the series in 1999 when a new class measure was introduced, but both measures can be observed for that year. This shows a rise in the proportion achieving good GCSEs between cohorts born in 1972 and 1977, though the odds ratio remains broadly stable, in line with the stability between the BCS and BHPS1 cohort. This plateaued for those born up to 1981, before falling sharply for cohorts born between 1983 and 1990. This timing completely coincides with the later BHPS data and LSYPE data shown in Table 4. There is a very high gradient in GCSE attainment across income groups for cohorts born in the 1970s and reaching 16 in the late 1980s and early 1990s, before declining markedly for those born in the 1980s and leaving school from 1997 onwards.

There must be some concern that this is driven by changes in examinations rather than underlying ability, literacy or numeracy skills. There has been a widespread concern that rising pass rates stem from 'grade inflation', which pushes more people into top grade categories. This would tend to narrow the observed income gradient, as a greater proportion of more affluent children will have already achieved a high number of $A^{*}$ $C$ grades. So we need to look at alternative measures not subject to this problem. One approach is to use more restrictive measures of GCSEs.

Appendix Table A1 replicates the main result for the BCS and LSYPE, of a declining social gradient in aged 16 educational attainment, using the total points score, which is a more continuous measure of GCSEs with no cut-off point at grade $C$, as points are assigned to all grades obtained. The coefficients indicate a significant decrease in the additional points associated with a doubling of family income for those born in 1970, compared to $1989 / 90$. However, the increasing numbers getting the top grades means this measure still has problems. LPM estimates of obtaining five $A^{*}-C$ grades and five $A^{*}-C$ grades, including maths and English, indicates a doubling of family income in the BCS is associated with an increase the probability of hitting these targets by around $15 \%$, compared to around $10 \%$ in the LSYPE. All decreases between the cohorts are significant at a $95 \%$ confidence level or higher. As the mean for those achieving $5+A *-C$ grades including maths and English is around ten percentage points lower than any $5 A^{*}-\mathrm{Cs}$, the similarity of the two measures is reassuring, demonstrating that capping is not the source of the narrowing of attainment gaps.

A more informative way to determine whether these findings are driven by changes in underlying ability and literacy and numeracy skills, rather than changes in examinations, is to examine data of $I Q$, literacy and numeracy scores and their relationship with family background across the cohorts. The relationship between family income and educational attainment can be expanded further back into the cohort member's childhood, to consider the relationship between family income and test scores. Blanden et al (2007) found that these test scores, measured at the beginning of secondary school, are strong predictors of earnings at thirty, and that the majority of the effects are coming through later educational attainment. Jencks' (1979) examination of a number of studies on this, finds correlations in the range of 0.40 and 0.6 between cognitive ability and educational achievement. Deary et al (2007) considers the correlation between Cognitive Ability Test (CAT) scores, and GCSE total points scores and best 8 GCSEs, and find an even stronger correlation in the UK of 0.69 for the point score and 0.72 for the best 8 GCSEs respectively. Using path analysis, they find an even stronger correlation of 0.81 between the underlying latent variable from the three CAT tests, and the underlying latent variable for general educational achievement. These test scores can be therefore thought of as a good early proxy for later educational attainment.

This data is not available in the BHPS and is limited in the LSYPE, but there is an additional ALSPAC birth cohort of children born in the old Avon area around Bristol in 1991/2, which can offer some insight here. Using comparable standardised reading and maths tests for the NCDS, BCS, LSYPE and ALSPAC, for children aged 10/11, Table 8 documents the mean test scores across the income quintiles. In addition, we have measures of IQ available in the NCDS, BCS and ALSPAC cohorts at ages 11,10 and 8 respectively, but not for the LSYPE. The mean score gap between the top and bottom income quintiles was 57 points for 10,52 for maths, and 56 for reading in the NCDS. These had risen to 81ppts, 84ppts and 88ppts respectively in the BCS, in line with the widening gaps in qualifications observed earlier. In the LSYPE, these had fallen back to 65ppts and 68ppts for maths and reading respectively, and in ALSPAC to 75ppts for IQ and 76ppts for maths and reading.

Table 9 documents the change in the univariate relationship with standardised family income across the four cohorts, and reports regression coefficients for these gradients. As with educational attainment, the 
NCDS is far less socially graded than the BCS in terms of test scores. An individual experiencing a $100 \%$ increase in family income, or moving from the $10^{\text {th }}$ to the $50^{\text {th }}$ percentile of the income distribution, is on average likely to score one fifth of a standard deviation higher on all three test scores. In comparison, the same income change in the BCS would increase test scores by one third of a standard deviation. These increases are statistically significant across the two cohorts (Panel 1 of Table 10).

Table 8. Average test score deviations from the standardised mean $(0,1)$ by income quintile for NCDS, BCS, LSYPE (1989-90) and ALSPAC (1991-92)

\begin{tabular}{lcccc} 
Variable & $\begin{array}{c}\text { NCDS } \\
\mathbf{1 9 5 8}\end{array}$ & $\begin{array}{c}\text { BCS } \\
\mathbf{1 9 7 0}\end{array}$ & $\begin{array}{c}\text { LSYPE } \\
\mathbf{1 9 8 9 / 9 0}\end{array}$ & $\begin{array}{c}\text { ALSPAC } \\
\mathbf{1 9 9 1 / 9 2}\end{array}$ \\
\hline IQ & & & & \\
\hline Inc quintile 1 & -0.2332 & -0.3262 & & -0.2554 \\
Inc quintile 2 & -0.0549 & -0.0445 & & -0.1041 \\
Inc quintile 3 & 0.0359 & 0.1124 & & 0.2165 \\
Inc quintile 4 & 0.0886 & 0.2350 & & 0.2690 \\
Inc quintile 5 & 0.3453 & 0.4965 & & 0.5019 \\
\hline Maths & & & & \\
\hline Inc quintile 1 & -0.2184 & -0.3030 & -0.2301 & -0.3583 \\
Inc quintile 2 & -0.0511 & -0.0712 & -0.1925 & -0.1038 \\
Inc quintile 3 & 0.0059 & 0.0931 & 0.0026 & -0.0093 \\
Inc quintile 4 & 0.0777 & 0.2284 & 0.2027 & 0.2314 \\
Inc quintile 5 & 0.3864 & 0.5379 & 0.4552 & 0.4099 \\
\hline Reading & & & & \\
\hline Inc quintile 1 & -0.2198 & -0.3409 & -0.2193 & -0.3558 \\
Inc quintile 2 & -0.0604 & -0.0795 & -0.1999 & -0.1259 \\
Inc quintile 3 & 0.0178 & 0.0987 & 0.0254 & 0.0376 \\
Inc quintile 4 & 0.0615 & 0.2723 & 0.2277 & 0.2359 \\
Inc quintile 5 & 0.3408 & 0.5461 & 0.4306 & 0.3963 \\
\hline
\end{tabular}

Unconditional means by income quintile, boys and girls

Table 9. Relationship between standardised family income and cognitive test scores for NCDS, BCS, LSYPE (1989-90) and ALSPAC (1991-92)

\begin{tabular}{lllll} 
Variable & $\mathbf{N C D S}$ & BCS & LSYPE & ALSPAC \\
& $\mathbf{1 9 5 8}$ & $\mathbf{1 9 7 0}$ & $\mathbf{1 9 8 9 / 9 0}$ & $\mathbf{1 9 9 1 / 9 2}$ \\
\hline IQ & 0.1963 & 0.2791 & & 0.2168 \\
& {$[0.011]^{* * *}$} & {$[0.013]^{* * *}$} & & {$[0.015]^{* * *}$} \\
$\boldsymbol{N}$ & 7733 & 5476 & & 4404 \\
Maths & 0.2025 & 0.2874 & 0.1758 & 0.2261 \\
& {$[0.011]^{* * *}$} & {$[0.013]^{* * *}$} & {$[0.010]^{* * *}$} & {$[0.014]^{* * *}$} \\
$\boldsymbol{N}$ & 7729 & 5485 & 9976 & 5419 \\
Reading & 0.1937 & 0.3003 & 0.1662 & 0.2207 \\
$N$ & {$[0.011]^{* * *}$} & {$[0.013]^{* * *}$} & {$[0.010]^{* * *}$} & {$[0.013]^{* * *}$} \\
Reading at 7 & 7732 & 5486 & 9895 & 5270 \\
& 0.1451 & & & 0.1773 \\
$N$ & {$[0.011]^{* * *}$} & & & {$[0.014]^{* * *}$} \\
\hline
\end{tabular}

Standard errors in parentheses, boys and girls, controls for parental age, parental age squared and gender

$* * *$ Indicates significance at the $99 \%$ confidence level, $* *$ is significant at the $95 \%$ confidence level, and * indicates a $90 \%$ confidence level. Family income is monthly net logged standardised family income. Income standardised to account for differential variation across cohorts. IQ at 11, 10 and 8 in the NCDS, BCS and ALSPAC respectively. Maths and reading measured at age 11 in all but the BCS (10).

Correlation between ALSPAC Key Stage reading at 11 and Clinic based Reading at 7 is 0.6766 
The LSYPE and ALSPAC test scores are however, consistent with a decrease in the social gradient in test scores for younger cohorts, with a significant decline in the relationship between family income and test scores from the BCS to both younger cohorts (panels 2 and 3 of Table 10). The social gradients in the two cohorts appear similar to those of the NCDS cohort, and panel 4 of Table 10 indicates there is no significant difference between the NCDS and ALSPAC. The additional ALSPAC clinically assessed reading test at 7 , exhibits a similar magnitude to the reading at 7 test in the NCDS, and similar patterns of a decrease in the social gradient from that of the BCS. This suggests that it is not the fact that age 11 reading and maths tests are derived from administrative data rather than school based assessments, that is driving the differences. IQ tests in ALSPAC are also undertaken in study clinics rather than being school-based. This further supports the notion of a reversal in fortunes of those from lower income families.

Table 10. Cross-cohort tests of significant differences from table 9 results

\begin{tabular}{|c|c|c|c|}
\hline Variable & $\begin{array}{l}\text { NCDS } \\
1958 \\
\end{array}$ & $\begin{array}{l}\text { BCS } \\
1970\end{array}$ & $\begin{array}{l}\text { Cross-cohort } \\
\text { Difference }\end{array}$ \\
\hline IQ & $\begin{array}{l}0.1963 \\
{[0.011]^{* * *}}\end{array}$ & $\begin{array}{l}0.2791 \\
{[0.013]^{* * *}}\end{array}$ & $\begin{array}{l}0.0827 \\
{[0.017]^{* * *}}\end{array}$ \\
\hline Maths & $\begin{array}{l}0.2025 \\
{[0.011]^{* * *}}\end{array}$ & $\begin{array}{l}0.2874 \\
{[0.013]^{* * *}}\end{array}$ & $\begin{array}{l}0.0849 \\
{[0.017]^{* * *}}\end{array}$ \\
\hline Reading & $\begin{array}{l}0.1937 \\
{[0.011]^{* * *}}\end{array}$ & $\begin{array}{l}0.3003 \\
{[0.013]^{* * *}}\end{array}$ & $\begin{array}{l}0.1065 \\
{[0.017]^{* * *}}\end{array}$ \\
\hline Variable & $\begin{array}{l}\text { BCS } \\
1970\end{array}$ & $\begin{array}{l}\text { LSYPE } \\
1989 / 90\end{array}$ & $\begin{array}{l}\text { Cross-cohort } \\
\text { Difference }\end{array}$ \\
\hline Maths & $\begin{array}{l}0.2874 \\
{[0.013]^{* * *}}\end{array}$ & $\begin{array}{l}0.1758 \\
{[0.010]^{* * *}}\end{array}$ & $\begin{array}{l}-0.1116 \\
{[0.017]^{* * *}}\end{array}$ \\
\hline Reading & $\begin{array}{l}0.3003 \\
{[0.013]^{* * *}}\end{array}$ & $\begin{array}{l}0.1662 \\
{[0.010]^{* * *}}\end{array}$ & $\begin{array}{l}-0.1341 \\
{[0.017]^{* * *}}\end{array}$ \\
\hline Variable & $\begin{array}{l}\text { BCS } \\
1970\end{array}$ & $\begin{array}{l}\text { ALSPAC } \\
1991 / 2\end{array}$ & $\begin{array}{l}\text { Cross-cohort } \\
\text { Difference }\end{array}$ \\
\hline IQ & $\begin{array}{l}0.2791 \\
{[0.013]^{* * *}}\end{array}$ & $\begin{array}{l}0.2168 \\
{[0.015]^{* * *}}\end{array}$ & $\begin{array}{l}-0.0623 \\
{[0.020]^{* * *}}\end{array}$ \\
\hline Maths & $\begin{array}{l}0.2874 \\
{[0.013]^{* * *}}\end{array}$ & $\begin{array}{l}0.2261 \\
{[0.014]^{* * *}}\end{array}$ & $\begin{array}{l}-0.0613 \\
{[0.019]^{* * *}}\end{array}$ \\
\hline Reading & $\begin{array}{l}0.3003 \\
{[0.013]^{* * *}}\end{array}$ & $\begin{array}{l}0.2207 \\
{[0.013]^{* * *}}\end{array}$ & $\begin{array}{l}-0.0795 \\
{[0.019]^{* * *}}\end{array}$ \\
\hline Variable & $\begin{array}{l}\text { NCDS } \\
1958\end{array}$ & $\begin{array}{l}\text { ALSPAC } \\
1991 / 2\end{array}$ & $\begin{array}{l}\text { Cross-cohort } \\
\text { Difference }\end{array}$ \\
\hline IQ & $\begin{array}{l}0.1963 \\
{[0.011]^{* * *}}\end{array}$ & $\begin{array}{l}0.2168 \\
{[0.015]^{* * *}}\end{array}$ & $\begin{array}{l}0.0205 \\
{[0.019]}\end{array}$ \\
\hline Maths & $\begin{array}{l}0.2025 \\
{[0.011]^{* * *}}\end{array}$ & $\begin{array}{l}0.2261 \\
{[0.014]^{* * *}}\end{array}$ & $\begin{array}{l}0.0235 \\
{[0.018]}\end{array}$ \\
\hline Reading & $\begin{array}{l}0.1937 \\
{[0.011]^{* * *}}\end{array}$ & $\begin{array}{l}0.2207 \\
{[0.013]^{* * *}}\end{array}$ & $\begin{array}{l}0.0270 \\
{[0.018]}\end{array}$ \\
\hline Reading at 7 & $\begin{array}{l}0.1451 \\
{[0.011]^{* * *}}\end{array}$ & $\begin{array}{l}0.1773 \\
{[0.014]^{* * *}}\end{array}$ & $\begin{array}{l}0.0322 \\
{[0.018]^{*}}\end{array}$ \\
\hline
\end{tabular}

Standard errors in parentheses, boys and girls, controls for parental age, parental age squared and gender

$* * *$ Indicates significance at the $99 \%$ confidence level, ${ }^{* *}$ is significant at the $95 \%$ confidence level, and * indicates a $90 \%$ confidence level. 


\section{Robustness of income measures and attrition}

As we use data from a number of different sources it is important that these are all comparable. A lot of work has been carried out previously on the comparability of the income measures in the NCDS and BCS (see Blanden 2004, Blanden et al 2008). As the main findings here focus on the BCS and LSYPE, appendix Table A2 documents the different income gradients associated with using different measures of income for these two cohorts.

The two main issues are over the technique used to turn the raw banded income into continuous data, and the transformation from gross income to net income required in both sources. The BCS has 11 bands of income data with $5 \%$ in the open top category. The LSYPE has 92 bands of data with $0.01 \%$ in the open top category. The Singh-Maddala transformation that is applied to the BCS banded data is a useful way of assigning those in the open top category within the band. As there are so few in the top category of the LSYPE, it is not necessary to apply this transformation. As can be seen from Table A2, the BCS results show that using midpoints of the bands, or an interval regression technique instead of the Singh-Maddala transformation, produces very similar coefficients. The interval regression technique is favoured as it weights an individual's position within a band and so, given there is little to choose between methods, this is the method chosen for the LSYPE.

Both the BCS and LSYPE are transformed from gross to net family income using the FES (Family Expenditure Survey) (1986) for the BCS and the FRS (Family Resources Survey) (2004) for the LSYPE, for households with children aged 10 to 16 . Gross and net household incomes are observable in these data sources, and therefore the average ratio for each band is used to impute a net income amount. In both cohorts, the transformation increases the relationship between family income and the total number of GCSEs when using non-standardised income. When the income is standardised, this deals with much of the associated differences in variation from applying this transformation, and the results in the BCS are almost identical. In the LSYPE, the net standardised income measure produces coefficients slightly below those from using a gross income measure.

Given that the LSYPE income measure is from the first wave of the study, there may be concerns that there is attrition by age 16 in the NCDS and $B C S$, that cannot have occurred in the LSYPE. Given that we would expect the attrition to be from lower income families, this could be driving the decline in the relationship between family background and educational attainment at 16 from the BCS to the LSYPE. Appendix tables $A 3$ and $A 4$ consider this issue, with panel 1 of table $A 3$ documenting the proportions of each of the father's social class at birth reporting income at 16 , and those not reporting income at 16 , and then panel 2 repeating this and including mother's class and parental education for the BCS. The main point to take from table A3 is that the attrition does not seem to be a particular problem in either cohort. It appears random across all social classes and education levels. For more stringent testing, the LSYPE cohort were weighted by their probability of leaving the sample by their parent's education, based on the findings from the BCS assuming similar patterns of attrition. Table A4 indicates that this makes no difference to the coefficient of the relationship between family income and the number of GCSEs grades $A^{*}$-C obtained in the LSYPE.

A further concern was that the LSYPE is the Longitudinal Survey of Young People in England whereas the other data sources also contain individuals from the rest of the UK. It could be the case that the results are driven purely by this selection if, for example, England had less educational inequality at GCSE level, than had Scotland, Wales and Northern Ireland. Therefore, the first row of Table 4 was replicated for the other data sources, restricting the samples to England only. As can be seen from table A5, this does not change the pattern at all. The significant decline remains, in the relationship between family background and educational attainment at 16 , for this restricted sample.

\section{Conclusions and discussion}

The above information presents a strong picture that the gradient of educational attainment at age 16 by family background (income or class), has lessened between generations born in the 1970s and those born in the 1980s and early 1990s. The government-based statistics on child attainment at age 16 are most commonly summarized by proportion of children attaining 5+ GCSEs grades $A^{*}-C$. This has been rising for nearly 20 years, from around $40 \%$ in the mid-1980s to nearly $60 \%$ by 2003 
the last year of our BHPS 2 sample). Whether this general rise in measured attainment reflects improved true attainment is disputed. Obviously as the proportion gets close to $100 \%$ any gradient must disappear, but in the middle range seen here, an expansion can still lead to larger increases in the top two quintiles than the bottom two.

The government-based data do not contain measures of family income, but there are two possible alternatives. The first is the Free School Meals eligibility, which applies to around $15 \%$ of children from among the poorest families, and the second is average attainment in schools with a higher or low proportion of FSM eligible children. However, even for these measures, the available data does not go very far back. It suggests a small closing of the attainment gap between FSM and non-FSM children in recent years, and a more marked closing of attainment gaps for schools serving a large proportion of FSM children. The Department of Children Schools and Families (DCSF) has used the Youth Cohort Studies to look at the relationship between social class and attainment at age 16, and suggests a narrowing of class gaps after 1997 (DCSF 2006 and Heath et al 2009). Our data, based on birth cohorts and the British Household Panel Survey, confirms this pattern using income data.

The picture of an improvement in equality of opportunity in terms of education attainment at age 16, is also mirrored in IQ and reading and maths test scores in two recent cohorts: LYPSE and ALSPAC. So for younger generations, the educational differences across family backgrounds at age 16, and in literacy and numeracy test scores at age 10/11, do appear to be equalising, but the picture for education after age 16 is less clear. Given the important role of education in accounting for levels of social mobility (Blanden et al 2007) there is a suggestion that this weakening of income gradients in educational attainment at age 16 may improve future mobility levels. However, the impact on future earnings remains to be seen, and will depend on whether the returns to different aspects of education change across time. As GCSEs are becoming more common and less graded by family background, their value in the labour market may also diminish. Indeed McIntosh (2006) finds evidence of this trend in the decline in the labour market returns to the number of GCSEs using LFS (Labour Force Survey) data from 1990-2005.
Whilst the timing of the closing of GCSE attainment gaps can be dated quite closely to cohorts reaching age 16 since 1995-97, or born since the early 1980s, the picture for test score data is less clear, as data is much less frequent but is in place for two cohorts born around 1990. At degree level, the picture of improvement in attainment gaps is far less clear.

The forces shaping the relationship between family income and educational attainment are widely thought to reflect inequality and the education system (see Blanden 2009, for a crosscountry review). The extent of child poverty (children growing up in low income households) rose from $13 \%$ in 1979 to $23 \%$ by 1987 when children born in the 1970s were moving through secondary school. It peaked at $27 \%$ in around 1996 before falling back to $22 \%$ in 2008 after the then Labour Government made a concerted drive to reduce it. This timing of the rise and more recent fall in child poverty thus only partially matched the timing observed. Whilst it is consistent with the growing importance of family background between the 1958 NCDS and 1970 BCS cohorts, the recent fall has come rather late to have had much affect of cohorts born in the early 1980s and sitting GCSEs in late 1990s. Further, the large scale investment in increasing spending on education as a share of GDP and attempts to reduce poverty and its effects on children since 1999 has been mostly heavily focused on younger children (the Sure Start programme and free $1 / 2$ nursery school places are focused on the under $5 \mathrm{~s}$, whereas class size reduction and tax credits have all been focused on children aged under 11). The impact on these children in terms of educational attainment at 16 is still some years away.

In terms of GCSE qualifications, improvements were clearly visible in the cohort preceding these investments and probably has more to do the reforms to age 16 qualifications introduced by Sir Keith Joseph in the Conservative era and started to come into effect in 1988 . This moved away from broadly a fixed proportion of children obtaining an O level in any subject to a fixed level which all children could theoretically achieve. This opened the way for a steady increase in the numbers of students achieving grades A-C since that date, but improved teaching and school quality have probably added to this dynamic. There have been many concerns raised that this rise is artificial grade inflation rather than a genuine improvement in 
standards, but the reductions in income gradients and test scores, including IQ scores, suggest that the narrowing social gradient in cognitive attainment cannot be entirely due to grade inflation in GCSEs but rather there has been a genuine reduction in educational inequalities for children leaving school since the early 1990s. However, the increasing frequency of GCSE achievement by children may serve to reduce their value in the labour market and higher education may be becoming the more important both in terms of well paid jobs and in terms of social patterning.

\section{Acknowledgements}

This work was funded by the ESRC Large Grant RES-060-23-0011 - An Examination of the Impact of Family Socio-economic Status on Outcomes in Late Childhood and Adolescence. The authors would like to thank the reviewers for comments to improve the paper.

\section{References}

Becker G and Tomes N. (1986) Human Capital and the Rise and Fall of Families. Journal of Political Economy, 85, 1141-1188.

Black S, Devereux, P and Salvanes K. (2008) Staying in the Classroom and Out of Maternity Ward? The Effect of Compulsory Schooling Laws on Teenage Births. The Economic Journal, 118, 1025-1054.

Blanden J. (2005) 'Essays on inter-generational mobility and its variation over time, place and family structure'. PhD thesis, University College, London.

Blanden J. (2009) How much can we learn from international comparisons of intergenerational mobility? CEE discussion paper DP0111.

Blanden J, Goodman A, Gregg P and Machin S. (2004) Changes in intergenerational mobility in Britain. In M. Corak ed. Generational Income Mobility in North America and Europe, Cambridge University Press, Cambridge.

Blanden J, Gregg P and Macmillan L. (2007) Accounting for intergenerational income persistence: Noncognitive skills, ability and education, The Economic Journal, 117, C43-C60.

Blanden J, Gregg P and Macmillan L. (2010) Intergenerational Persistence in Income and Social Class: The Impact of Within-Group Inequality. CMPO Working Paper 10/230.

Blanden J and Machin S. (2008) Up and down the Generational Income Ladder in Britain; Past Changes in Future Prospects. National Institute Economic Review No. 205.

Blanden J and Machin S. (2004) Educational inequality and the expansion of UK higher education. Scottish Journal of Political Economy, 51(2), 230-249.

Brewer M, Ratcliffe A and Smith S. (2007) Does Welfare Reform Affect Fertility? Evidence from the UK. CMPO Working paper 07/177.

Corak M. (2006) Do poor children become poor adults? Lessons from a cross-country comparison of generational earnings mobility. IZA Discussion Paper No. 1993.

Dahl G and Lochner L. (2008) The Impact of Family Income on Child Achievement: Evidence from the Earned Income Tax Credit NBER Working Paper No. 14599.

Dearden L, Machin S and Reed H. (1997) Intergenerational mobility in Britain. The Economic Journal, 107(440), 4764.

Dickson M. (2009) The Causal Effect of Education on Wages Revisited. IZA Discussion Paper 4419.

Deary IJ, Strand S, Smith PK and Fernances C. (2007) Intelligence and educational achievement. Intelligence, 35, 13-21.

Ermisch J and Francesconi M. (2004) Intergenerational mobility in Britain : new evidence from the BHPS. In M Corak (ed) Generational Income Mobility in North America and Europe, Cambridge University Press, Cambridge.

Ermisch J and Nicoletti C. (2005) Intergenerational earnings mobility: changes across cohorts in Britain. ISER Working Paper 2005-19. Colchester, University of Essex, Colchester.

Galindo-Rueda F and Vignoles A. (2005) The declining relative importance of ability in predicting educational attainment. Journal of Human Resources, 40(2), 335-53.

Grawe N. (2004) The 3-day week of 1974 and earnings data reliability in the Family Expenditure Survey and the National Child Development Survey. Oxford Bulletin of Economics and Statistics, 66(3), 567-579.

Gregg P, Macmillan L and Nasim B. (2010) The impact of the 1980s recession on educational attainment. Mimeo.

Jäntti M, Bratsberg B, Røed K, Raaum O, Naylor R, Osterbacka E, Bjorklund A and Eriksson T. (2006) American exceptionalism in a new light: a comparison of intergenerational earnings mobility in the Nordic countries, the United Kingdom and the United States. IZA Discussion Paper No. 1938.

Heath N, Lupton R and Salter E. (2009) Social class inequalities in education in England under New Labour. In J Hills, T Sefton and K Stewart. eds. Towards a more equal society? Poverty, inequality and policy since 1997. The Policy Press, Bristol.

Jencks C. (1979) Who gets ahead? The determinants of economic success in America. Basic Books, New York. 
McIntosh, S. (2006) Further Analysis of the Returns to Academic and Vocational Qualifications. Oxford Bulletin of Economics and Statistics, 68(2), 225-251.

Mincer J. (1974) Schooling, experience, and earnings. National Bureau of Economic Research, New York.

Meghir C and Palme M. (2005) Educational Reform, Ability and Parental Background). American Economic Review, 95(1), 414-424.

Milligan K and Stabile M. (2008) Do child tax benefits affect the wellbeing of children? Evidence from Canadian Child Benefit Expansions, National Bureau of Economic Research, WP 14624.

Oreopoulos P. (2006) Estimating Average and Local Average Treatment Effects of Education when Compulsory Schooling Laws Really Matter. American Economic Review, American Economic Association, 96(1), 152175.

Oreopoulos P and Page M. (2006) The Intergenerational Effects of Compulsory Schooling. Journal of Labor Economics, 24(4), 729-760.

Oreopoulos P, Page M and Huff Stevens A. (2008) The Intergenerational Effects of Worker Displacement. Journal of Labor Economics, 26(3), 455-483.

Schoon I. (2006) Risk and resilience. Adaptations in changing times. Cambridge University Press,

Singh S and Maddala G. (1976) A Function for Size Distribution of Incomes. Econometrica, 44(2), 963-970.

Solon G. (1999) Intergenerational mobility in the labor market. In O Ashenfelter and D Card. eds. Handbook of Labour Economics, Volume 3A, North Holland, Amsterdam.

Solon G. (2002) Cross country Differences in Intergenerational Earnings Mobility. Journal of Economic Perspectives, 16(3), 59-66.

\section{Appendix}

\section{Robustness check on educational attainment at 16}

Table A1. Relationship between standardised family income and a range of O-levels or equivalent measures at 16

\begin{tabular}{|c|c|c|c|}
\hline Variable & $\begin{array}{l}\text { BCS } \\
1970\end{array}$ & $\begin{array}{l}\text { LSYPE } \\
1989 / 90\end{array}$ & $\begin{array}{l}\text { Cross-cohort } \\
\text { Difference }\end{array}$ \\
\hline Number of O-levels & $\begin{array}{l}1.1315 \\
{[0.046]^{* * *}}\end{array}$ & $\begin{array}{l}0.9336 \\
{[0.035]^{* * *}}\end{array}$ & $\begin{array}{l}-0.1979 \\
{[0.060]^{* * *}}\end{array}$ \\
\hline O-level point score & $\begin{array}{l}38.365 \\
{[1.965]^{* * *}}\end{array}$ & $\begin{array}{l}31.97 \\
{[1.500]^{* * *}}\end{array}$ & $\begin{array}{l}-6.3973 \\
{[2.7570]^{* *}}\end{array}$ \\
\hline Five $A^{*}$-C grades & $\begin{array}{l}0.1447 \\
{[0.007]^{* * *}}\end{array}$ & $\begin{array}{l}0.0929 \\
{[0.005]^{* * *}}\end{array}$ & $\begin{array}{l}-0.0517 \\
{[0.008]^{* * *}}\end{array}$ \\
\hline $\begin{array}{l}\text { Five } A^{*}-C \text { grades } \\
\text { incl. eng + maths }\end{array}$ & $\begin{array}{l}0.1530 \\
{[0.009]^{* * *}}\end{array}$ & $\begin{array}{l}0.1038 \\
{[0.005]^{* * *}}\end{array}$ & $\begin{array}{l}-0.0493 \\
{[0.010]^{* * *}}\end{array}$ \\
\hline
\end{tabular}

Standard errors in parentheses, boys and girls, controls for parental age, parental age squared and gender

$* * *$ Indicates significance at the $99 \%$ confidence level, ${ }^{* *}$ is significant at the $95 \%$ confidence level, and * indicates a $90 \%$ confidence level.

\section{Robustness check on comparability across income measures}

Table A2. Relationship between various family income measures and the number of O-levels or equivalent at grade $A^{*}-C$ at 16 for the BCS and LSYPE

\begin{tabular}{|c|c|c|c|c|}
\hline & Gross & & Net & \\
\hline & BCS & LSYPE & BCS & LSYPE \\
\hline Variable & 1970 & $1989 / 90$ & 1970 & $1989 / 90$ \\
\hline \multicolumn{5}{|c|}{ Non-standardised income } \\
\hline \multirow[t]{2}{*}{ Singh Madalla } & 1.8619 & & 2.3081 & \\
\hline & {$[0.076]^{* * *}$} & & {$[0.095]^{* * *}$} & \\
\hline$N$ & 5428 & & 5428 & \\
\hline \multirow[t]{2}{*}{ Mid-points } & 1.9566 & 1.0835 & 2.3530 & 1.1571 \\
\hline & {$[0.080]^{* * *}$} & {$[0.039]^{* * *}$} & {$[0.096]^{* * *}$} & {$[0.044]^{* * *}$} \\
\hline$N$ & 5428 & 10925 & 5428 & 10925 \\
\hline Interval & 1.9453 & 1.0838 & 2.3340 & 1.1581 \\
\hline regression & {$[0.080]^{* * *}$} & {$[0.039]^{* * *}$} & {$[0.097]^{* * *}$} & {$[0.043]^{* * *}$} \\
\hline$N$ & 5428 & 10935 & 5428 & 10935 \\
\hline
\end{tabular}


(Table A2 cont'd)

\begin{tabular}{lllll}
\multicolumn{5}{l}{ Standardised income } \\
\hline Singh Madalla & 1.1348 & & 1.1315 \\
& {$[0.046]^{* * *}$} & & {$[0.046]^{* * *}$} & \\
$\boldsymbol{N}$ & 5428 & & 5428 \\
$\mathbf{M i d}-$ points & 1.1399 & 1.0559 & 1.1414 & 0.9308 \\
& {$[0.046]^{* * *}$} & {$[0.038]^{* * *}$} & {$[0.046]^{* * *}$} & {$[0.035]^{* * *}$} \\
$\boldsymbol{N}$ & 5428 & 10925 & 5428 & 10925 \\
Interval & 1.1358 & 1.0579 & 1.1369 & 0.9336 \\
regression & {$[0.047]^{* * *}$} & {$[0.038]^{* * *}$} & {$[0.047]^{* * *}$} & {$[0.035]^{* * *}$} \\
$\boldsymbol{N}$ & 5428 & 10935 & 5428 & 10935 \\
\hline
\end{tabular}

Standard errors in parentheses, boys and girls, controls for parental age, parental age squared and gender

${ }^{* * *}$ Indicates significance at the $99 \%$ confidence level, ${ }^{* *}$ is significant at the $95 \%$ confidence level, and * indicates a $90 \%$ confidence level.

\section{Robustness check on attrition in the NCDS and BCS compared to the LSYPE}

Table A3. Proportions of Permanent indicators at birth for the full sample, those reporting income at 16 and those not reporting income at 16

\begin{tabular}{|c|c|c|c|}
\hline NCDS & Full sample & With income & Without income \\
\hline \multicolumn{4}{|c|}{ Father's social class at birth } \\
\hline Social class 1 & 4.53 & 4.06 & 4.99 \\
\hline Social class 2 & 12.96 & 11.74 & 14.14 \\
\hline Social class 3 NM & 9.67 & 9.47 & 9.89 \\
\hline Social class $3 \mathrm{M}$ & 50.90 & 51.66 & 50.17 \\
\hline Social class 4 & 12.12 & 12.95 & 11.32 \\
\hline Social class 5 & 9.83 & 10.12 & 9.49 \\
\hline Total & 16,468 & 8,006 & 8,430 \\
\hline \multicolumn{4}{|c|}{$\begin{array}{l}\text { Proportions by parental class at birth, boys and girls } \\
\text { BCS }\end{array}$} \\
\hline & Full sample & With income & Without income \\
\hline \multicolumn{4}{|c|}{ Father's social class at birth } \\
\hline Social class 1 & 5.20 & 5.24 & 5.17 \\
\hline Social class 2 & 12.08 & 12.33 & 11.92 \\
\hline Social class 3 NM & 12.20 & 14.03 & 11.03 \\
\hline Social class $3 \mathrm{M}$ & 47.83 & 47.10 & 48.29 \\
\hline Social class 4 & 15.68 & 15.05 & 16.08 \\
\hline Social class 5 & 7.01 & 6.25 & 7.50 \\
\hline Total & 15773 & 6146 & 9627 \\
\hline \multicolumn{4}{|c|}{ Mother's social class at birth } \\
\hline Social class $1 \& 2$ & 13.99 & 14.55 & 13.63 \\
\hline Social class 3 NM & 44.69 & 47.27 & 43.03 \\
\hline Social class $3 \mathrm{M}$ & 8.03 & 7.43 & 8.41 \\
\hline Social class 4 & 31.27 & 29.12 & 32.66 \\
\hline Social class 5 & 2.01 & 1.63 & 2.26 \\
\hline Total & 10476 & 4117 & 6359 \\
\hline
\end{tabular}


(Table A3 cont'd)

\begin{tabular}{|c|c|c|c|}
\hline \multicolumn{4}{|c|}{ Father's highest education level } \\
\hline No quals & 9.56 & 7.31 & 11.01 \\
\hline NVQ level 1 (left 15) & 56.33 & 56.83 & 56.01 \\
\hline NVQ level 2 (left 16) & 14.14 & 14.97 & 13.60 \\
\hline NVQ level 3 (left 17/18) & 11.07 & 11.55 & 10.76 \\
\hline NVQ level 4/5 (left 19+) & 8.90 & 9.34 & 8.62 \\
\hline Total & 16213 & 6347 & 9866 \\
\hline \multicolumn{4}{|c|}{ Mother's highest education level } \\
\hline No quals & 7.86 & 5.65 & 9.24 \\
\hline NVQ level 1 (left 15) & 58.15 & 57.83 & 58.35 \\
\hline NVQ level 2 (left 16) & 16.46 & 18.21 & 15.37 \\
\hline NVQ level 3 (left 17/18) & 11.59 & 12.01 & 11.32 \\
\hline NVQ level 4/5 (left 19+) & 5.95 & 6.30 & 5.72 \\
\hline Total & 17017 & 6552 & 10465 \\
\hline
\end{tabular}

Table A4. Relationship between standardised family income and the number of O-levels or equivalent at grade $A^{*}-C$ at 16 for the LSYPE, weighted by attrition by parental education from the BCS

\begin{tabular}{lll} 
Variable & $\begin{array}{l}\text { Non- } \\
\text { weighted }\end{array}$ & Weighted \\
\hline Number of O-levels & 0.9374 & 0.9377 \\
$\left(\right.$ A $^{*}$ C) & {$[0.035]^{* * *}$} & {$[0.034]^{* * *}$} \\
\hline$N$ & 10605 & 10605 \\
\hline
\end{tabular}

Non-weighted numbers only differ from table 4 as this sample requires parental education information Standard errors in parentheses, boys and girls, controls for parental age, parental age squared and gender

*** Indicates significance at the $99 \%$ confidence level, ${ }^{* *}$ is significant at the $95 \%$ confidence level, and * indicates a $90 \%$ confidence level.

\section{Robustness check on sample for England only for NCDS, BCS and BHPS}

Table A5. Relationship between standardised family income and the number of O-levels or equivalent at grade $A *-C$ at 16 for a sample of those in England only in the NCDS, BCS and BHPS

\begin{tabular}{llllll} 
& NCDS & BCS & BHPS 1 & BHPS 2 & BHPS 3 \\
Variable & $\mathbf{1 9 5 8}$ & $\mathbf{1 9 7 0}$ & $\mathbf{1 9 7 5 - 1 9 8 0}$ & $\mathbf{1 9 8 1 - 1 9 8 6}$ & $\mathbf{1 9 8 7 - 1 9 9 0}$ \\
\hline Number of O-levels & 0.7363 & 1.1591 & 1.1196 & 0.7755 & 0.8874 \\
(A*-C) $_{\boldsymbol{N}}^{[0.040]^{* * *}}$ & {$[0.051]^{* * *}$} & {$[0.163]^{* * *}$} & {$[0.270]^{* * *}$} & {$[0.265]^{* * *}$} \\
\hline
\end{tabular}

Standard errors in parentheses, boys and girls, controls for parental age, parental age squared and gender

$* * *$ Indicates significance at the $99 \%$ confidence level, $* *$ is significant at the $95 \%$ confidence level, and * indicates a $90 \%$ confidence level.

\section{Endnotes}

\footnotetext{
'The coefficient when combining BHPS 2 and BHPS 3 is 0.9777 (0.188)

ii The coefficient of staying on post-16 on income for combined BHPS 2 and BHPS 3 group is 0.0979 (0.022) which is statistically significantly different from the corresponding BCS coefficient at a $10 \%$ level of significance.
} 
